\title{
LXIX. Continuation of the reply to Mr. Riddle's remarks on Mr. Meikle's paper "On the lunar observations"
}

\author{
Mr. Meikle
}

To cite this article: Mr. Meikle (1819) LXIX. Continuation of the reply to Mr. Riddle's remarks on Mr. Meikle's paper "On the lunar observations" , Philosophical Magazine Series 1, 54:260, 401-405, DOI: $10.1080 / 14786441908652256$

To link to this article: http://dx.doi.org/10.1080/14786441908652256

电 Published online: 29 Jul 2009.

Submit your article to this journal $\pi$

Џll Article views: 2

Q View related articles $\sqsubset$ 


\section{[ 401$]$}

LXIX. Continuation of the Reply to Mr. RIDDLE's Remarks on Mr. MeIKLE's Paper "On the Lunar Olservations." By Mr. MrikLe.

\section{To Mr. Tilloch.}

SiR, - $\mathbf{I}_{\mathrm{N}}$ your last Number I hope I have cleared my paper on the lunar observations from some of the groundless charges of Mr. Riddle. There still, however, remain several other things to be noticed. For the most part Mr. R. has been at great pains to prove trifles which every body knows, and which I never denied. But passing over this at present, I come to consider the learned demonstration which he einploys to prove that my method of finding the true altitude of the centre is not more accurate than that method in which the reduced semidiameter is used*. With regard to this, I need only observe, that if he had given my paper a fair reading, he might have seen plainly that it is not the method with the reduced semidiameter " on which I animadvert with so much severity," (page 35 , line 28 ,) but the common slovenly method almost in universal use, in which the reduction of the semidiameter is not used at all ; and at the altitude of $7^{\circ}$ this reduction on a mean amounts to $18^{\prime \prime}$, which is just the error complained of. I there called it a needless error, and so I do still ; for the very accurate method which I recommended, is attended with as little labour as the most slovenly method can be.

Again: In giving his " vulgar test of arithmetical computation," he does very unfair to compare my method with what he calls " the common method." Now, in the common method, as every body knows, the reduction of the semidiameter by refraction is neglected altogether; and it was for this very neglect that I. "6 animadverted on it with so much severity." I must however remark, that I have never, throughout my whole paper, although Mr. Riddle would fain insinuate it, inculcated the observance of such nicety at sea; where, as is too well known, some seamen are tolerahly content if they get the altitude within half a degree of the truth; and for such, the common method is certainly more than sufficiently correct. But still, when at any time persons, who are not aware of its incorrectness, make a landing, and attempt to determine their geographical situation, it must of course be erroneous. It was for this very reason that I so deservedly censured the method of finding the latitude by the pole star. In giving an approximation, it is surely the least thing an author can do, to mention that it is not theoretically correct,

* That the apparent altitude of the centre may also be got correctly by this method, is what I never once called in question.

Vol. 54. No. 260. Dec. 1819. C c and 
and within what limits it may be used with safety. It is undoubtedly owing to some such causes as the above, that one navigator finds water where another placed the land; or that islands have been known to dive and swim alternately at pleasure.

It must, no doubt, be acknowledged that another person will often discover what the author of a paper did not himself $\mathrm{ob}-$ serve; and in this respect Mr. R. has shown much acuteness, since most of the things he has discovered do not exist in my paper at all. In order to set me in as odious a light as possible, he says, "It would indeed appear that I am not aware that the cenlral distance of the objects is what is required." But it is past his power to produce the "appearance" of any such thing; and after all the contempt he affects to throw on the "excentric point," he is not able to show that it will ever produce any " error" whatever. The rule however which I gave on page 37, is plainly meant as approximate, and not as strictly correct in low altitudes.

In perusing my paper in your last Number, which was written in too great haste, I am really sorry to find that I have expressed myself very incorrectly about the augmentation of the moon's diameter. I was led into that mistake by adhering too closely to Mackay's remark, which Mr. Riddle says is " theoretically true;" whereas it is no such thing, as he may soon find at his leisure. What I have said about the augmentation being greatest in a vertical direction is entirely a mistake; but as the error, and indeed the whole dispute, is merely about a small fraction of a second, it is useless to say any thing further about a quantity that can do neither good nor ill.

With regard to what I formerly advanced respecting the principles of the quadrant, and on which Mr. R. animadverted with so much groundless severity, I would beg to observe, that in explaining the principles of any instrument, it is certainly of the last importance to assign to each particular part its proper use or effect; otherwise, it does not deserve the name of an explanation at all; and can at best convey vague or erroneous ideas of the nature of the instrument. Had Mr. Riddle himself been the first to discover the popular mistake in question, that would have altered the case. But it would indeed have been too much for any other person but himself to have had the merit of discovering " " that a mistaken idea was generally entertained respecting the theory of an instrument of such importance."

I shall now proceed to demonstrate that the halving of the observed angle is completely effected by the first, the single veflection; and in so doing, I hope I shall not be taxed with producing a demonstration of the principles of the instrument which is 
to be had in every corner, as $\mathrm{Mr}$. R. has done with great ability in your Number for October, although it did not in the least suit his purpose. For the original intention of that demonstration was merely to show that the instrument only gives half the observed angle; and on no account to prove, what is not true,that the halving is owing to the doulle reflexion. To talk of the " actual construction of the instrument" is nothing to the purpose; for that construction includes several other glasses which are just as much concerned in halving the angle as the horizon glass is. Indeed we might on the same grounds ascribe that effect to the frame's being constructed of wood or brass. But the grand thing to be kept in mind is, that the "instrument as actually constructed and used," involves nothing on which the halving of the angle depends but the single reflexion of the indexmirror.

Let $M I$ be the position of the index at zero, or when the altitude of an object $\odot$ is $=0$; and let $\odot \mathrm{M}$ a ray from the object impinge against the mirror $M$, and be reflected to $\mathrm{R}$, making, by the principles of optics, the angle of incidence $\odot \mathrm{MP}=\mathrm{PMR}$ the angle of reflexion.

Suppose now that the object has attained a certain altitude $\odot M \odot^{\prime}$, and that we turn the index I till the ray $\odot^{\prime} M$ is reflected to $R$, making as before $\odot^{\prime} M P^{\prime}=P^{\prime} M R$.

It is then evident that the angle $P M P^{\prime}=P^{\prime} M R-P M R=\frac{1}{2} \odot^{\prime} M R$ $-\frac{x}{2} \odot M R=\frac{x}{2} \odot^{\prime} M \odot$. But PMI $=90^{\circ}=\mathrm{P}^{\prime} \mathrm{MI}^{\prime} ;$ from each take

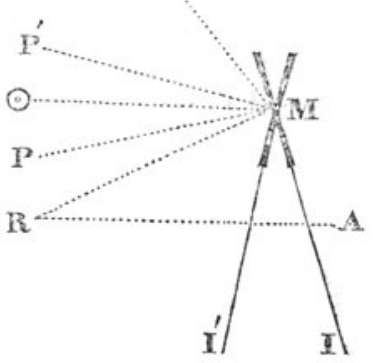
$P \mathrm{MI}^{\prime}$, and $\mathrm{I}^{\prime} \mathrm{M} \mathrm{I}=\mathrm{P}^{\prime} \mathrm{MP}=\frac{\mathrm{z}}{2} \odot^{\prime} \mathrm{M} \odot=\frac{\mathrm{x}}{2}$ observed angle.

The same thing may be shown in several ways; but since the halving of the observed angle is thus completely effected by the first, the single reflexion, it is clear that the only use of the second mirror fixed at $R$, is to reflect the ray $M R$ in a direction parallel to $\odot \mathrm{M}$; so that an observer at $\mathrm{A}$ might see the object in coutact with the horizon.

Each mirror, therefore, serves as distinct a purpose from that of the other, as it is possible for any two mirrors to do in one instrument; and to confound the use of the one with that of the other, is to explain a simple principle into a mystery, where no real mystery exists.

Upon the whole, Mr. Riddle is certainly very bright on the quadrant. "It is true," says he, "that if a ray of light be re-

$$
\mathrm{C} \text { c } 2
$$




\section{Continuation of the Reply to Mr. Riddle's Remurks}

flected from a revolving mirror, the angle described by the refiected ray will be double of that described by the mirror,"-a statement meaning neither more nor less than that the halving of the observed angle is completed by the single reflexion of that one revolving mirror. And yet in a little after he would like to prove the contrary ; but on account of the impossibility of the task, he contents himself with trying to palm the popular error in question, on the demonstration he had copied from some elementary work; and, strange to relate, he at length brings out the extraordinary conclusion, that there is nothing "vague or insignificant" in ascribing the above effect to the "double reflexion!"

Mr. R. lastly admits, though reluctantly, that I had correctly stated the error of certain tables *, but that I had " disingenuously converted that into an argument against putting confidence in any tables of the kind." Now this accusation is totally unfounded; since it is to his own candour and moderation that I owe its extension to " any tables of the kind." My own words are :- " It is not difficult to perceive what confidence ought to be put in such tables;" - obviously meaning the tables only which contained the gross error, and by no means any tables of the kind. It is then Mr. R. himself who " has betrayed the aberration from rectitude of intention," by disingenuously laying so many erroneous things to my charge, which he might have been content to have attributed to his own misconstruction.

I am, sir, Your most obedient servant,
Berners street, Dec. 3, 1819.

P.S.-In your last Number, Mathematicus, among other things, accuses me of advancing three distinct properties of the ellipsis " with an air of novelty." Now that this accusation, so far as " novelty" is concerned, must be very incorrect, is obvious to any one who merely looks at the uncertain mode in which I have announced that proposition.

With regard to my other crime of not reading, I would beg to inform him, that $I$ had turned over several very complete treatises on Conic Sections, some of those he mentions not excepted; but then I was only in quest of the other two properties, without concerning myself at all about the third "long known" one, until writing out the demonstration, I merely marked it down as an obvious consequence of the other two ; and I had scarcely sent away that paper, when on turning over the second volume of Pro-

- This error is of no trifling nature, since by it a ship may appear to change her latitude sixteen miles at the end of twelve hours, although she do not stir out of the spot, and that too in any part of the globe.

fessor 
fessor Leslie's Mathematics, about to be published, I found the property which has been so' 'clong known;" and of course perceived that I had laid myself open to an accusation so often chargeable on correspondents to periodical mathematical works; viz. the obliging the public with articles that are not new. However, as this long-known property is immediately deduced from the other two without any additional harangue, I hope I shall obtain pardon from the reasonable part of your readers for the commission. of such a weighty offence.

My investigation of the other two properties has still a decided advantage over that proposed by your correspondent; in that it is founded on properties of the ellipsis to be found in every treatise, and familiar to such as know very little of Conic Sections. This end I had in view, in giving it the present form.

My remarks, however, on periodical mathematical works were not, as he supposes, so much aimed at such works themselves ; nor yet at their editors, who, I well know,-have enough to mind besides; but my strictures were chiefly intended for the proposers of useless puzzling questions so very detrimental to the reputation of such works, and so much complained of by many who are not at the trouble of doing so publicly.

I readily agree that every encouragement ought to be afforded to periodical mathematical works, as of the utmost advantage to the progress of science; while on the otherhand, useless puzzling questions cannot be too much condemned.

Before proceeding, however, to solve his questions, I would beg to ask, Why he has allotted me the four last, rather than any of the others. Was it, because one of them (the 12th) affords a most striking instance of the truth of my former remarks, and of the little consideration with which such questions are too often proposed? The fact is, that question is altogether absurd and impossible, so long as the nature and diameter of the cylinder. as well as the exact dimensions of the table-land are not given. Any one might see this at once who has ever heard of the law of gravitation- "a discovery of the great Newton which he did not owe to reading."

This therefore I consider a complete solution to the 12th question, and hope the Editor of the Ladies' Diary will have the goodness to insert it for the amusement of the ladies.

H. M. 